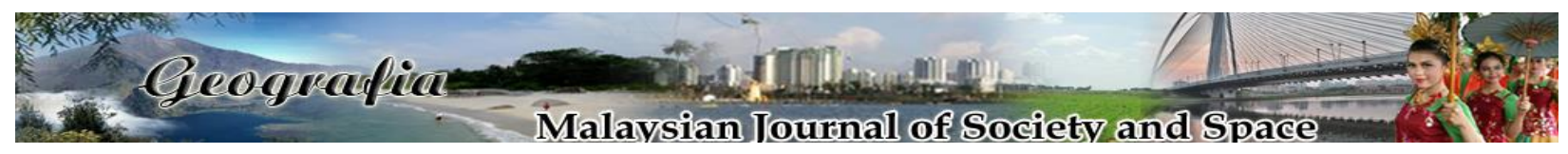

\title{
Understanding energy efficiency using a socioeconomic framework: The case of paddy farming in Malaysia
}

\author{
Siti 'Aisyah Baharudin \\ Universiti Sains Malaysia \\ Correspondence: Siti ‘Aisyah Baharudin (email: sab16@usm.my)
}

Received: 01 July 2020; Accepted: 25 January 2021; Published: 27 February 2021

\begin{abstract}
The agriculture sector is one of the contributors to energy use either as production input or bioenergy output. The utilization of energy use is based on the Cobb-Douglas production theory. Nevertheless, several factors affecting energy use in paddy production include fuel for running machinery, electricity for irrigation, fertiliser for improving soil fertility, pesticides for pest control, and planting seeds. Albeit the relationship between energy use and agricultural productivity is well examined in the literature, the results are mixed. Some studies argue that higher energy use tends to higher agricultural productivity, while others found that energy use efficiency leads to higher productivity. This study investigates farmers' socioeconomic status in paddy production based on the statistical analysis of paddy productivity, farmers' income, and production cost in Malaysia's MADA granary areas. Besides, it utilizes the Energy Analysis approach to analyze energy efficiency based on inputs use selected by farmers. The results show that the harvested area does not affect the farmers' income, while productivity positively affects farmers' income. Production costs are not influenced by socioeconomic variables such as ownership and harvested area as they depend on farmers' willingness to pay for inputs. The energy efficiency in MADA is 6.35 , which indicates that farmers can obtain at least six times larger paddy productivity compared to the inputs used in production activities.
\end{abstract}

Keywords: Energy efficiency, farmers, paddy machinery, productivity, rice, socioeconomic

\section{Introduction}

Arguments on the relationship between agriculture and energy resources started in the 1970s, which question whether the agricultural sector could be a significant energy producer through the conversion of grains, manure, crop residues, and other substances into methane, ethanol, and related fuels (Buttel \& Youngberg, 1982). On the other hand, there are issues of energy consumption, such as fuel and fertiliser in producing paddy and crop. Recently, research related to energy efficiency in the wider agricultural sector, especially the food industry's use of energy by 
$30 \%$ in production activities (Pimentel \& Pimentel, 2008). The reliable supply of energy is one of many essential requirements for significant growth in Malaysia's agricultural productivity.

Energy consumption is required at the activities of production in the paddy industry. They are two categories of energy use in rice production either directly or indirectly. The first category includes agricultural workers whether owners or hired laborers and fuel either petrol or diesel used by the machine. The second category includes seeds used in planting either manually or transplants, as well as inputs used in crop management activities, such as fertilisers, pesticides and farm machinery such as tractors, transplanters and harvester (Shafie, 2016).

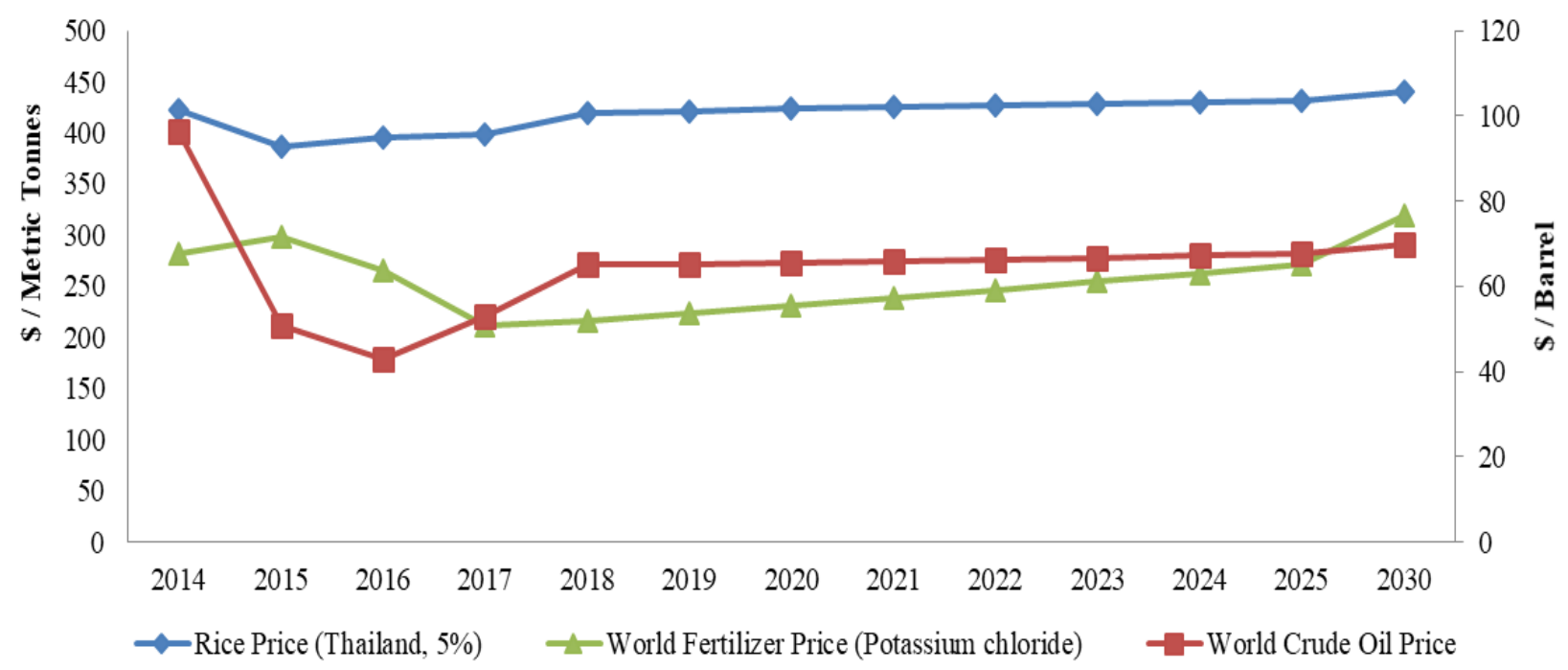

Source: Gusev, 2018

Figure 1. World crude oil price, Fertiliser price and rice price (2017-2030)

There is a long-run relationship between energy input (crude oil prices and fertiliser prices) with the agricultural output (rice price) in Figure 1. Rice prices had increased over the year followed by increases in world crude oil and fertiliser prices. By comparison, the price change of fertiliser was $3.4 \%$ compared to world crude oil prices. It shows, the indirect effect seems to be higher than the direct impact on paddy productivity. Among the factors increasing energy costs are caused by the pull of demand and supply. As a result, production costs increased by up to $45 \%$, rice productivity is reduced up to $10 \%$ in the short term (Siti 'Aisyah Baharudin, 2018) and a reduction in the area planted to conserve inefficient machinery (Masuda, 2017).

Paddy cultivation in Malaysia is not only essential to provide food to the people but also to ensure food security. Farmers' income and paddy productivity are important indicators in determining the socioeconomic level of paddy farmers. Despite years of protection and extensive government support, self-sufficiency level (SSL) hovers around 70\% since the 1990s, and paddy productivity grew at about $1 \%$ per year (MoA, various years). Besides, the shortage of fossil fuels and an increase in petroleum prices will change the future trend of energy use. The contribution of energy into paddy production has to be established to estimate the impact on the paddy and rice industry. This study attempts to investigate the socio-economics of paddy farmers in the MADA granary areas. Besides, it uses an energy analysis approach to analyze energy use and energy efficiency of paddy production in the study area. 


\section{Literature review}

Alam et al. (2011) analysed the relationships between the paddy yields and the socio-economic characteristics of the farmers in the Integrated Agricultural Development Area (IADA), NorthWest Selangor, Malaysia. The data for this project were collected through a sample survey of farmers raising paddy in the eight parts of North West Selangor, Malaysia's Integrated Agricultural Development Region (IADA). Paddy producing farmers were the target group of the survey. The survey was a structured questionnaire which was taken under the direct supervision of IADA officials by regular IADA authority enumerators. This study conducted multiple cross-sectional regressions of OLS for analysis of the data. A variety of farmers' socio-economic and physical characteristics have significant impacts on the production of paddy.

Boniphace et al. (2015) analysed the socio-economic determinants of inputs used by smallholder farmers in the major rice-producing regions of Tanzania. The sample of 842 households from high rice-producing areas (Mbeya, Morogoro, Shinyanga, Mwanza and Tabora) in Tanzania was taken from data based on the Tanzania National Panel Survey (NPS) for 20102011. Variables related to household socio-economic characteristics were defined and computed. Descriptive analyses were used to summarise the information collected. The Probit model was used to evaluate the determinants of the use of inputs among agricultural households. The study found that the probability of using agricultural inputs increased with the level of education, the number of crops produced, livestock, farm income, while the overall number of animals and nonfarm income of the household decreased. The study also found a difference between regions in input preferences.

Nabavi-Pelesaraei et al., (2018) assess the energy cycle and life cycle of paddy production environmental considerations. Besides, the researchers also want to develop the models for the prediction and modelling of paddy production rate, using Artificial Neural Networks and Adaptive Neuro-Fuzzy Inference System (ANFIS). The initial inputs are all types of agricultural input parameters, energy supply pipes, applied equipment and machinery, farmland, paddy farms' yields are randomly collected from 240 paddy producers through a face-to-face questionnaire. In this study, the energy balance analysis method and the LCA method were implemented. Results show that 44.34 per cent of diesel fuel consumes the largest share of energy. The results of LCA show that paddy production contributes to a $\mathrm{CO} 2 \mathrm{eq}$ emission of $1166.09 \mathrm{~kg}$ per ton of paddy. Furthermore, fertilisers are a significant source of water pollution.

Pelesaraei et al., (2017) tried to determine Iran's energy flow, cumulative exergy, and paddy life cycle. This analysis also aims to define energy consumption optimisation using Data Envelopment Analysis (DEA) and Multi-Objective Genetic Algorithm (MOGA) to boost energy efficiency. This research also studied the optimum energy consumption pattern in paddy production. This study collects and extracts data from 240 paddy farms in Iran's Guilan Province. Sampling method and the LCA method have been used in this research. Inputs are human labour, machinery, diesel, chemical fertilisers, biocides, electricity and seed. Results indicate that using DEA and MOGA, energy savings are $21.15 \%$ and $71.63 \%$.

Muazu et al. (2015) researched to evaluate the energy audit in Malaysia's wetland paddy. This research was undertaken to assess the distributions of six essential resources, human, fuel, machinery, seeds, fertiliser and pesticides. An on-farm energy analysis has been conducted on 40 wetland farms. Data for this study were collected in the cropping season of Sungai Besar, Sabah Bernam district of Selangor from March-July 2013. All the farm inputs and the reported output from each farm were translated using a suitable conversion coefficient into equivalent energy 
values. The sensitivity analysis showed that machinery energy has the most significant impact on production and that approximately $84 \%$ of the total energy input used by farmers during the entire growing period was from non-renewable fossil resources.

Mohammadi et al. (2014) compared and assessed six crops in northern Iran to know about energy efficiency and GHG emissions. Energy analysis in the system of crop production enables an effective method of farming concerning energy parameters. The data used in the study were obtained through a customised interview with farmers whose main activity was the primary production of wheat, barley, canola, soybean, paddy and corn in the area. A questionnaire was designed to collect the information required for the various input applications. Energy inputs include human labour, diesel fuel, crops, chemical fertilisers, waste, biocides, power, machinery and water. Similar studies and figures have been collected by various individuals and organisations, such as the Ministry of Agriculture of Iran. The results showed that crop yield and production energy were not significantly affected by field size, while machine efficiency improved considerably as field size increased. The study also indicates that paddy planting emits the highest CO2 emissions from crops with a methane contribution of around $60 \%$.

Alluvione et al. (2011) identified components of the agricultural system with particularly high energy use to improve efficiency. Furthermore, this study aims to evaluate the effectiveness of various crops in the use of inputs and to evaluate the capacity of alternative integrated management practices. This study compared the energy performance of three cropping systems; low-input integrated farming, integrated farming following European Regulations, and conventional farming and energy fluxes were estimated using crop management and production records for biomass. This research used a methodology of 'process analysis' for analysis of the energy. The inputs counted in this study were divided into two: i) mechanisation inputs that included the use of tractor and equipment, and consumption of fuel and lubricant; and ii) agronomic data consisting of crop propagation materials, fertilisers, pesticides, and irrigation water. The result indicated that the best technique for reducing energy inputs is to balance $\mathrm{N}$ fertilisation with actual crop requirements and to adopt minimum tillage.

\section{Research methodology}

Paddy production begins with land preparation for every season. At this stage, the use of tractors and human labour are needed for tillage and land levelling. The second stage is the seeds planting, which is done through either direct seeding or transplanting, based on the choice of farmers. There are three activities undertaken in crop management, namely; i) applying fertilisers, ii) spraying pesticides and iii) water control in paddy fields. Once the seeds mature, farmers will harvest the paddy to be sent to a nearby rice mill, ideally BERNAS or a private mill. The rate of energy use explains the price and quantity for each energy input as well as input cost incurred in during paddy production process. Energy use in the irrigation is excluded as it is borne by the government.

\section{Data Collection}

This study uses data collection techniques through the distribution of purposely-structured questionnaires, informal discussions and interviews with the farmers, machine suppliers and MADA officer. The data and information were collected through a field survey (depth interview). An in-depth survey was conducted in MADA granary areas in the main season of 2019. MADA 
area in Kedah and Perlis states involves the Muda Irrigation Plan is the largest paddy plantation in Malaysia. The MADA area represents $37 \%$ of paddy production, $24.1 \%$ of paddy area and $32 \%$ of farmers in Malaysia. The objective of this survey is to access energy consumption in the paddy production activities. The data included hours, litre and kilograms of production input including direct and indirect energy.

\section{Sampling Method}

Based on the estimation on the total population involved in paddy production under each province, a purposive random sample of farmers was selected. This technique is appropriate because it allows the researcher to determine the specific characteristics of the respondents to meet the objectives of the study. The representative farmers were chosen according to many considerations that could make possible successful achievement of the study objectives and enable smooth running of field surveys. These considerations include farmers who are using direct seeding method in planting activity and Farmers who are registered with the Pertubuhan Peladang Kawasan (PPK) and MADA. Sample size from each locality is based on its population size. Hinton (1995) state 25 respondents were sufficient for social studies using in-depth interview techniques. Therefore, this study selected 10 respondents for the pilot study to test survey questions and 40 respondents for the actual survey.

\section{Statistical Analysis}

There are two research objectives calculated in this study. The first is to measure the socioeconomic level of MADA farmers based on the discussion of key variables namely paddy productivity, farmer's income and production cost. The second objective is based on the calculation of the amount of output and input energy that determines energy consumption. Meanwhile, energy efficiency is calculated based on the energy equilibrium in Table 1.

Table 1. Energy equivalents of inputs and output in paddy production

\begin{tabular}{llc}
\hline Category & Type $($ Unit) & Energy equivalent $\left(\mathrm{MJ} \mathrm{unit}^{-1}\right)$ \\
\hline Energy Output & 1.Rice/Paddy $(\mathrm{kg})$ & 17.00 \\
Energy Input - Fuel & a) Diesel $(\mathrm{L})$ & 47.80 \\
& b) Petrol $(\mathrm{L})$ & 46.30 \\
Energy Input - Labor & $(\mathrm{h})$ & 2.00 \\
Energy Input - Machinery & $\left(\mathrm{kg} \mathrm{yr}{ }^{\mathrm{a}}\right)$ & $6.00-8.00$ \\
Energy Input - Fertiliser & a) Nitrogen $(\mathrm{N})(\mathrm{kg})$ & 78.10 \\
& b) Phosphorus $\left(\mathrm{P}_{2} \mathrm{O}_{5}\right)(\mathrm{kg})$ & 17.40 \\
& c) Potassium $\left(\mathrm{K}_{2} \mathrm{O}\right)(\mathrm{kg})$ & 13.70 \\
Energy Input - Pesticides & d) Manure $(\mathrm{kg})$ & 0.47 \\
& a) Herbicides $(\mathrm{kg})$ & 85.00 \\
& b) Insecticides $(\mathrm{kg})$ & 229.00 \\
Energy Input - Seed & c) Fungicides $(\mathrm{kg})$ & 115.00 \\
& d) Rodenticides $(\mathrm{kg})$ & 28.6 \\
\hline
\end{tabular}

${ }^{\text {a }}$ Economic life of machine (year)

Source: Mittal et al., (1985), Stout (1990) and Pishgar-Komleh et al., (2011) 
The formula for calculating energy consumption and energy efficiency has been modified from Flinn \& Duff (1985) in accordance with the study area. The inputs are fuel, labor, machinery, fertilisers, pesticides and seeds, while the output is the paddy yield as shown in equation (1) and (2). The rate of energy use is a function of $\mathrm{kg} / \mathrm{ha}$. Energy efficiency can be determined based on equation (3) with the unit used is $\mathrm{MJ} / \mathrm{ha}$.

Total energy output $\left(\mathrm{MJ} \mathrm{ha}^{-1}\right)=$ Paddy productivity $\left(\mathrm{kg} \mathrm{ha}^{-1}\right)$ x Energy equivalent $\left(\mathrm{MJ} \mathrm{kg}^{-1}\right)$

Total energy input $\left(\mathrm{MJ} \mathrm{ha}^{-1}\right)=\left[\right.$ Fuel use $\left(\mathrm{L} \mathrm{ha}^{-1}\right)+$ Labour use $\left(\mathrm{h} \mathrm{ha}^{-1}\right)+$ Machinery use $\left(\mathrm{kg} \mathrm{ha}^{-1}\right)$ + Fertiliser use $\left(\mathrm{kg} \mathrm{ha}^{-1}\right)+$ Pesticides use $\left(\mathrm{kg} \mathrm{ha}^{-1}\right)+$ Seed $\left.\left(\mathrm{kg} \mathrm{ha}^{-1}\right)\right]$ $\mathrm{x}$ Energy equivalent for each inputs (MJ)

Energy efficiency $\left(\mathrm{MJ} \mathrm{ha}^{-1}\right)=$ Total energy output $\left(\mathrm{MJ} \mathrm{ha}^{-1}\right) /$ Total energy input $\left(\mathrm{MJ} \mathrm{ha}^{-1}\right)$

\section{Results and discussion}

The research analysis is divided into two sections. The former comprises the socio-economic analysis that focuses on paddy productivity and farmers' income, while the latter embraces the production cost analysis of energy efficiency that focuses on input consumption of paddy production.

\section{Analysis of socioeconomic}

The research sample contains 40 Malay male farmers in the MADA. About $15 \%$ of the farmers aged between 31 to 40 years old, and $12 \%$ between 41 to 50 years old. Only three farmers were aged more than 60 years old, which they counted for the lowest percentage of $7 \%$ of the total farmers, while farmers aged between 51 to 60 years old counted for the highest percentage of $66 \%$ of the total farmers. Hence, it indicates that the older generation continues to be involved in paddy farming activities. The collected data show that the percentage of full-time farmers, which equals $61 \%$, is higher than the percentage of part-time farmers, which equals $39 \%$. Farmers who are involved on a full-time basis in farm management actually have another job at the same time, such as doing small business or rubber tapping. The most extended years of experience that the farmers have in paddy farming activities shows that $34 \%$ of them have between 21 to 30 years of experience. Farmers with 1 to 10 years of experience have the same percentage as farmers who have between 31 to 40 years of experience, about $22 \%$ of them are experienced in organizing paddy fields for more than 40 years.

Educational subgroup comparisons presented in this study are divided into four categories: the Malaysian Higher School Certificate (STPM and equivalent), the Malaysian Certificate of Education (SPM and equivalent), secondary school, and primary school. About 15 in 40 farmers did not finish high school, which is the highest percentage of the educational level of farmers in the MADA area at $37 \%$. About $29 \%$ of the farmers only attended secondary school and obtained Lower Secondary Assessment (PMR), followed by 17\% of those who hold STPM and equivalent qualification. In terms of marital status, the data indicate that the proportion of who have married is higher $(95 \%)$ than those who are still single (5\%). Surprisingly, only 15 farmers $(37 \%)$ out of total respondents have joined a few workshops and talks that related to paddy plantation. The 
majority of them have yet to join any programs. The dependency category shows that the majority of farmers $(83 \%)$ bear one to five family members.

\section{a. Paddy productivity}

The majority of the respondents $(66 \%)$ own one to five hectares of paddy field, followed by $22 \%$ of the respondents owning less than one hectare. Only $12 \%$ of them have more than five hectares of paddy field. Similar to those who have more than 10 hectares. The category of the ownership of paddy land divided into self-owned land, rented land, and both. A total of $41 \%$ of respondents cultivate paddy on their self-owned land, while only $34 \%$ of them rent land from other owners. On the other hand, about $25 \%$ of them use both self-owned land and rented land. There are two types of planting methods, including direct seeding and transplanting. In this research, it happened to be that all farmers use the direct seeding method instead of the transplanting method due to its advantages, which allow faster and easier plantation compared to the transplanting method. In terms of the type of soil, there are three grades, including grade A, grade B, and grade C. $70 \%$ of the respondents agreed that the soil in that area is grade B. It reflects that the quality of the soil is average. Grade A stands for good quality, while grade $\mathrm{C}$ stands for poor soil quality.

Figure 2 indicates that $44 \%$ of the farmers receive paddy productivity of fewer than 5 tonnes per hectare. Meanwhile, $51 \%$ of farmers showing productivity at 5 to 6 tones per hectare in line with Malaysia's target of five tonnes per hectare. The highest productivity indicates that the farmer had followed the program organized by MADA using MR297 seeds and a production cost of 1,300 per hectare. Hence, it is clear that the farm size and paddy productivity are not correlated.

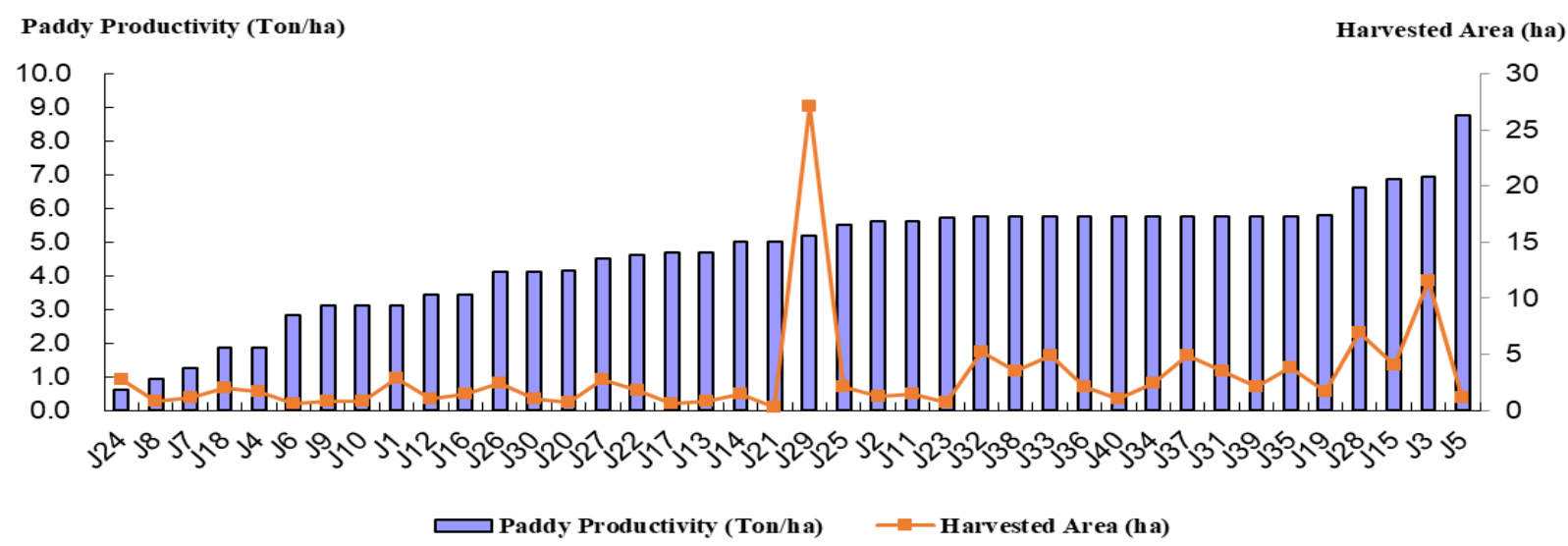

Figure 2: Paddy productivity in MADA (2019)

\section{b. Farmers income}

This survey result show that about $44 \%$ of farmers under MADA earn between MYR2,001 to MYR5,000 per hectare in Figure 3. Approximately 27\% of them earn MYR5,001 to MYR10,000, followed by $29 \%$ earn less than MYR2,000 per hectare. Eleven farmers earning more than MYR500 per hectare, eight of them using self-owned land, and their productivity is above five 
tonnes per hectare. It can be concluded that the size of the field does not affect the income of the farmers, but productivity could increase the farmers income.

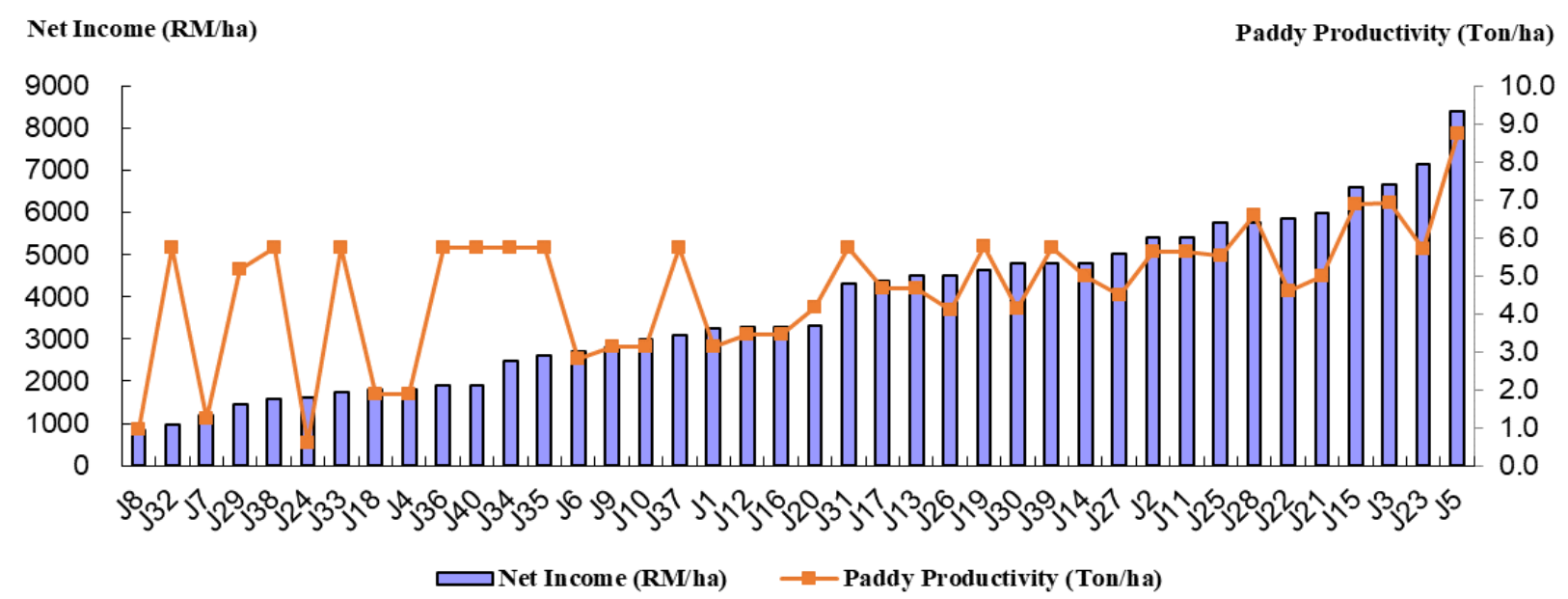

Figure 3: Farmers income in MADA (2019)

Interestingly, the majority of the respondents (90\%) choose to sell their paddy to the private miller instead of Padiberas Nasional Berhad (BERNAS). BERNAS was privatized in January 1996 which is a monopoly on rice trading activities in Malaysia undertaken by the National Rice Board in the Malaysian paddy and rice industry (BERNAS, 2019). Based on such a figure, several factors lead to this result, such as easy access to money and the price of the paddy sold. Most of the farmers respond that their choice also depends on the third wheeler (people that connect the farmer and the private miller). Deduction rates do not play a significant role in their selection because the rate between both millers around $20 \%$ to $23 \%$ depending on the quality of harvested paddy.

\section{c. Production cost}

The cost of paddy production is divided into three categories, namely rental, wages, and input costs. Rental cost includes the cost of field rental and tractor rental, whereas wages are the transportation cost for fertilisers to fields and paddy to factories and labor wages. The cost of inputs includes the cost of purchasing seeds and pesticides as well as additional fertilisers. Based on Figure 4, the average of production cost in MADA area around RM1990 per hectare with the highest cost at RM3861 per hectare and the lowest cost at RM636 per hectare. The rents range from MYR115.20 per hectare to MYR144.00 per hectare for farmers who cultivate the paddy field with the use of rented land. In addition to the cost of renting a tractor for plowing, leveling the land and repairing the boundary. The tractor rental rate to repair the limit is MYR7.20 per hectare. While tractor rental rates for plowing purposes range between MYR75.00 to 120.00 per hectare depending on the frequency of plowing. The cost of rental of leveling ranges between MYR90.00 to MYR120.00 per ha. Finally, the rental cost of harvesting ranges between MYR316 per hectare to MYR38.88 per hectare and this is an adjusted rate for all farmers. Laborers are hired for the process of cutting straw, leveling the land, repairing the borders, embroidering, fertilizing, and poisoning. Labor wages range from MYR4.32 per hectare to MYR11.52 per hectare. Some farmers choose to do the process on their own due to the small size of their field. Thus, labor wages for farmers who do the process themselves are not included in the paddy production cost. 

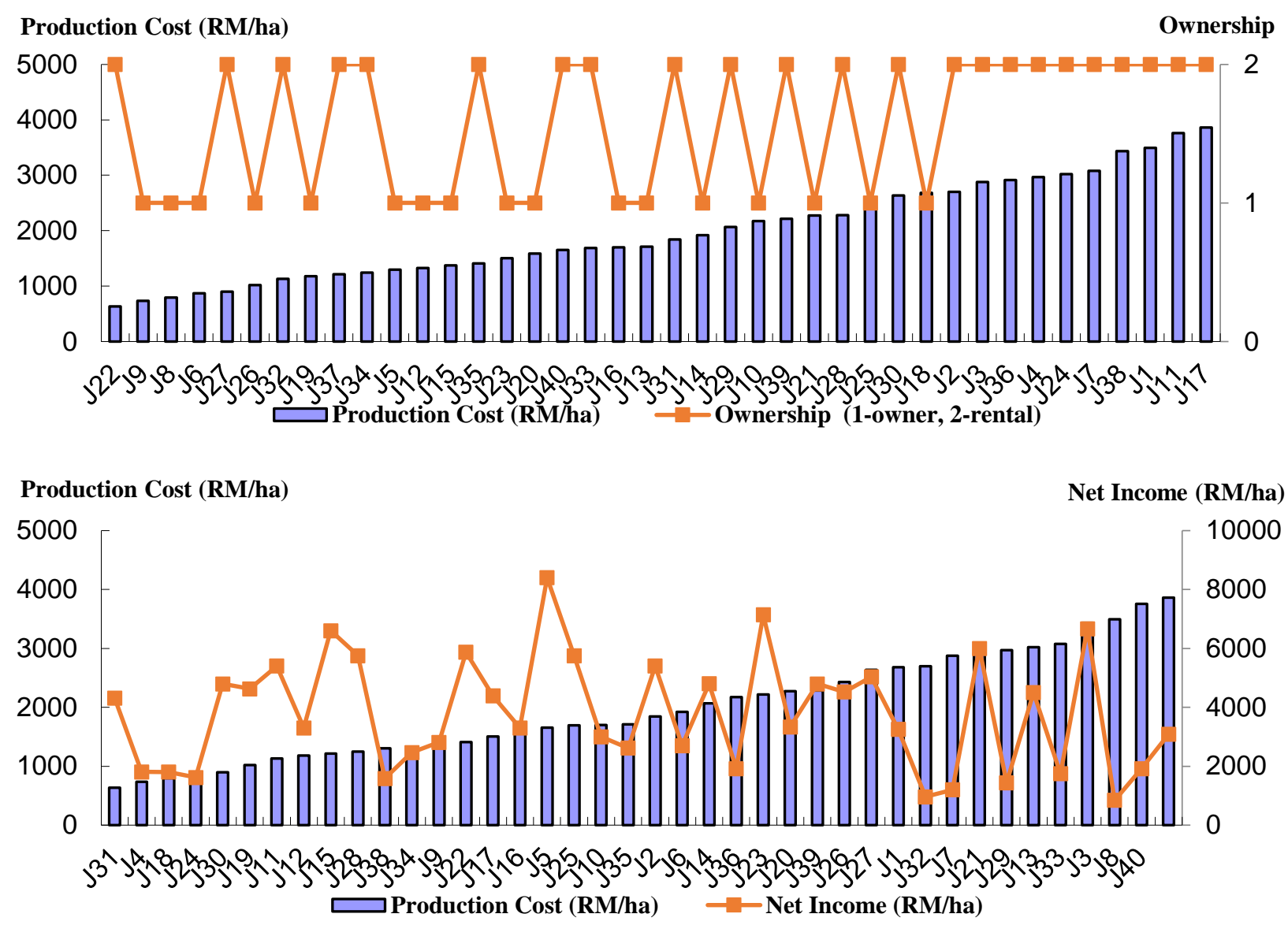

Figure 4: Production cost in MADA (2019)

The variety of seeds that the farmers used is important for farm yield. One of the varieties is MR297, and it is the latest version of seed developed by the Malaysian Agricultural Research and Development Institute (MARDI). The majority of the respondents (76\%) use the MR297 seed as it can increase the yield up to $70 \mathrm{~kg}$ per hectare. Besides, the price of these seeds at MYR32/20kg is also considered affordable compared to the others, such as MR220 CL2 at MYR48/20kg. One of the respondents said that he made a significant saving by using the MR297 as it requires only a small amount of pesticide. 35 out of 40 respondents also use MR220 CL2. The respondents said they use these seeds to prevent the weedy rice. Weedy rice or "Malay: padi angin" does not produce grains and grows together with paddy seeds. Wind paddy is a major problem for farmers as pesticides used to eliminate wind paddy will also affect the growing productive paddy. Other types of seeds are MR 284, MR 263, MR 305, MR 219, and Vietnam Kebal. However, Vietnam Kebal is not sold in the market. A respondent said that he uses his self-made formula to come out with this version. He chooses to come out with this idea as it helps to increase his yield up to 4 tonnes per hectare. Besides, the Vietnam Kebal improves resistance to major insect pests and diseases, including blasts.

Each respondent has a different total cost due to their willingness to pay for the inputs. In terms of fertiliser, the respondents receive three types of fertiliser as a subsidy from the government, including Urea, Sebatian, and Compound (NPK). The total cost for these three is 
MYR118.61. However, the farmers are still in need of using another fertiliser, such as a booster that depends on the condition of the paddy farm. An example of the fertiliser is Renox, and it costs MYR50 per bottle. The nearest Association for Shopping Complex and High-rise Management is known as (PPK) delivers the fertiliser. Fuel delivery costs MYR1.20 per bag. The farmers need to be present at the nearest PPK office to pay for the cost of shipping the fertiliser before they have it delivered to them. In this research, all the respondents in the area use MYR200 per hectare pesticide coupons and an additional MYR25 per hectare coupon. Moreover, rice transportation costs to the factory calculated as each bag of paddy (9 tonnes) are charged a transportation fee between MYR2.00 to MYR4.00. Based on the information obtained, the transportation cost for paddy to be moved to the factory will be deducted upon the factory payment to the farmer. The cost of paddy inputs is used in calculating energy consumption, including seeds, pesticides and fertiliser costs.

\section{Analysis of Energy Efficiency}

Energy consumption in MADA paddy production area was used as the sample study in this study. The rate of energy use explains the price and quantity for each energy input as well as input cost incurred in during paddy production activities. The rent of paddy machinery increases due to equipment maintenance cost, machine driver salary and fuel price factors. Labor is still widely used in the MADA area taking into account the farmers or employed workers undertake the planting activity manually. During crop management activity, a total of 3-4 times fertilization composed of $\mathrm{N}, \mathrm{P}_{2} \mathrm{O}_{5}, \mathrm{~K}_{2} \mathrm{O}$ and manure is done. There are differences in the use of different types of pesticides depending on region and type of pests in MADA. MR297 and MR 220 CL2 are used to calculate energy use because this seed is the most popular seed type among farmers.

The results depicted that the average of total output energy use and input energy used in MADA was about 69,139 MJ per hectare and 11,050 MJ per hectare, respectively. While energy efficiency is 6.35. This result shows that the efficiency of rice production in MADA is still modest. Based on the current consumption of inputs, farmers are able to produce 6 times the productivity of rice. There is an excess of energy use in rice production if it exceeds 1 . However, this figure is still within the range of crop efficiency based on the study by Soni et al., (2013) which shows the ratio of 12:21 to 13.7 still indicates efficiency. Among the major contributors to this ratio are farmers who have a small land area of 1 to 2 hectares compared to other farmers. This is because they will reduce the use of inputs in producing output. As a result, the productivity of this group of farmers is lower and affects their energy efficiency in rice production. The results of this study are also supported by Nassiri and Singh, 2009 which shows a high correlation between input usage and energy efficiency.

\section{Conclusion}

This research suggests three policy recommendations to increase paddy productivity through energy efficiency and reduce waste of energy use in paddy production that can be stated as follows: 1) extension services is a network between farmers and key players in the rice industry in Malaysia. Although the farmers know their farm better than the extension agents, there should be a tripartite among farmers, the research community, and agencies involved in the paddy and rice industry to emphasize the need for research and the delivery of extension services. This is important because some farmers are affected by social behavior in their technological adoption. This leads to a waste 
of energy use, such as excessive use of energy due to inadequate knowledge of the machinery, the use of old and refurbished machinery, and high payment of machinery rental costs. The example of extension services such as transfer of high yield seed from research labs to farms can improve energy efficiency, increase farmers income and increasing food security; 2) the government should consider encouraging the development of the domestic input industry due to a lack of local inputs industry and the continued reliance on imported inputs. The capabilities of the local input industry can provide better and cheaper input alternatives for farmers, hence, increased energy efficiency, and 3) the government should focus on the development of small and medium enterprises in the industry of paddy and rice. This is because farmers' income is more secure and stable through business opportunities and not dependent on production alone. It is in line with the government's policy in agriculture sector to increase farmers income and productivity as well as guarantee food security.

\section{Acknowledgement}

This research was fully funded by Short-Term Grant, Universiti Sains Malaysia (USM) (304/PSOSIAL/6315147).

\section{References}

Alam, M. M., Siwar, C., Talib, B., \& Mohd Ekhwan, T. (2011). The Relationships between the Socioeconomic Profile of Farmers and Paddy Productivity in North-West Selangor, Malaysia. Asia-Pacific Development Journal, 18(1), 161-173.

Alluvione, F., Moretti, B., Sacco, D., \& Grignani, C. (2011). EUE (energy use efficiency) of cropping systems for a sustainable agriculture. Energy 36, 4468-4481.

BERNAS. (2019, 7 5). The Commitment to Gatekeeping the Padi and Rice Industry. Retrieved from Padiberas Nasional Berhad: http://www.bernas.com.my/bernas/index.php/ component/content/article/14-presreleases/27-08-july-2019-the-commitment-togatekeeping-the-padi-and-rice-industry.

Boniphace, N. S., Fengying, N., \& Chen, F. (2015). An analysis of smallholder farmers' socioeconomic determinants for inputs use: A case of major rice producing regions in Tanzania. RJOAS, 2(38).

Buttel, F. H., \& Youngberg, I. G. (1982). Energy policy and agriculture. Proceedings of the Academy of Political Science, 34(3), 122-133. DOI: 10.2307/1173734.

Flinn, J. C., \& Duff, B. (1985). Energy analysis, rice production systems, and rice research. IRRI Research Paper Series (Philippines) No.114.

Gusev, M., (2018) Crude Oil Price Forecast: 2018, 2019 and Long Term to 2030. Retrieved from: http://comstat.comesa.int/infographics/yxptpab/crude-oil-price-forecast-2018-2019and-long-term-to-2030.

Hinton, P. R. (1995). Statistics explained: A guide for social science students. London and New York.

Masuda, K. (2018). Energy Efficiency of Intensive Rice Production in Japan: An Application of Data Envelopment Analysis. Sustainability, 10, 120. 
Muazu, A., Yahya, A., Ishak, W.I.W., \& Khairunniza-Bejo, S. (2015). Energy audit for sustainable wetland paddy cultivation in Malaysia. Energy, 87, 182-191.

Nabavi-Pelesaraei, A., Rafiee, S., Mohtasebi, S.S., Hosseinzadeh-Bandbafha, H., \& Chau, K. (2017). Energy consumption enhancement and environmental life cycle assessment in paddy production using optimization techniques. Journal of Cleaner Production, 162, 571-586.

Nabavi-Pelesaraei, A., Rafiee, S., Mohtasebi, S.S., Hosseinzadeh-Bandbafha, H., \& Chau, K. (2018). Integration of artificial intelligence methods and life cycle assessment to predict energy output and environmental impacts of paddy production. Science of the Total Environment, 631-632, 1279-1294.

Pimentel, D., and Pimentel, M.H. (2008). Energy inputs and crop production in developing and developed countries. Food, Energy and Society: CRC Press, Taylor and Francis Group, 137-159.

Mittal, V. K., Mittal, J. P., \& Dhawan, K. C. (1985). Research Digest on Energy Requirements in Agricultural Sector (Technical Bulletin No. ICAR/AICRP/ERAS/85-1). Punjab Agricultural University, Punjab, India.

Mohammadi, A., Rafiee, S., Jafari, A., Keyhani, A., Mousavi-Avval, S.H., \& Nonhebel, S. (2014). Energy use efficiency and greenhouse gas emissions of farming systems in north Iran. Renewable and Sustainable Energy Reviews, 30, 724-733.

Nassiri, S.M., \& Singh, S. (2009). Study on energy use efficiency for paddy crop using data envelopment analysis (DEA) technique. Applied Energy, 86, 1320-1325.

Shafie, S. M. (2016). A review on paddy residue-based power generation: Energy, environment and economic perspective. Renewable and Sustainable Energy Reviews, 59, 1089-1100.

Siti 'Aisyah Binti Baharudin (2018). The impact of world crude oil price on the liberalisation of Malaysia's paddy industry. Geografia-Malaysian Journal of Society and Space, 14(4). 308-321.

Soni, P., Sinha, R., \& Perret, S.R. (2018). Energy use and efficiency in selected rice-based cropping systems of the Middle-Indo Gangetic Plains in India. Energy Reports, 4, 554564.

Pishgar-Komleh, S.H., Sefeedpari, P., \& Rafiee S. (2011). Energy and economic analysis of rice production under different farm levels in Guilan province of Iran. Energy, 36, 58245831. Retrieved from http://doi:10.1016/j.energy.2011.08.044.

Stout, B. A. (1990). Handbook of Energy for World Agriculture. Elsevier Applied Science, London. 